RUNNING HEAD: SYSTEM THREAT AND CONSERVATIVE SHIFT AMONG

ADOLESCENTS

Conservative Ideological Shift among Adolescents in Response to System Threat

\author{
Jojanneke van der Toorn \\ Utrecht University, The Netherlands \\ Leiden University, The Netherlands
}

\author{
John T. Jost \\ New York University, U.S.A. \\ Benjamin Loffredo \\ Yale College 2012, Los Angeles, CA, USA
}

For author queries: Prof. Dr. Jojanneke van der Toorn

Heidelberglaan 1, 2584CS Utrecht, The Netherlands

j.m.vandertoorn@uu.nl

Please note: This is the accepted manuscript after peer review. This version of the article may not completely replicate the final version published in Zeitschrift für Psychologie. It is not the version of record and is therefore not suitable for citation. 


\begin{abstract}
We examined conservative ideological shift among adolescents by assessing the effect of different types of threat on the self-reported political orientation of 183 New York City high school students and investigated the mediating role of system justification. Participants read one of three newspaper passages: (1) a system-related passage that described flaws in the American social, economic, and political system; (2) a self-related passage that described the deleterious health effects of cellphone use; or (3) a control passage that described house plant cultivation. Participants then completed measures of system justification and political orientation. As hypothesized, a threat to the system (but not the self) increased self-reported conservatism indirectly through its effect on system justification. This suggests that when the overarching social system is threatened, adolescents may be drawn to conservative ideology and that this is attributable, at least in part, to a heightened desire to defend and bolster the societal status quo.
\end{abstract}




\section{Conservative Ideological Shift among Adolescents in Response to System Threat}

Research on the structure and functions of political ideology suggests that a range of dispositional and situational factors can lead people to express more politically liberal or conservative preferences (Jost, Glaser, Kruglanski, \& Sulloway, 2003). People who possess stronger needs for order, structure, and certainty and who perceive the world as more dangerous tend to be more conservative. On the other hand, people who are especially open to new experiences tend to be more liberal. Contextual influences on political ideology have also been observed. In the aftermath of September 11, 2001, for example, heightened perceptions of uncertainty and threat appear to have increased the appeal of conservative ideas (Bonanno \& Jost, 2006; Nail \& McGregor, 2009; Schüller, 2015). Laboratory experiments provide direct support for conservative shift following exposure to threat (Nail, McGregor, Drinkwater, Steele, \& Thompson, 2009; Thórisdóttir \& Jost, 2011). At the same time, specific psychological mechanisms that are responsible for the effects of threat on political attitudes have not been adequately identified. The study of political attitudes in youth groups represents a rapidly expanding area of scholarship, but it is still the case that children and adolescents are much less studied than adult populations. In the current article, we aim to fill these gaps in the literature by (1) investigating whether conservative shift resulting from system-level threats is due to increased system justification motivation, (2) distinguishing empirically between threats directed at the system and threats directed at the self, and (3) examining political orientation in adolescents.

\section{Conservative Shift}

Following an exhaustive meta-analytic review of the correlates of political orientation, Jost and colleagues (2003) concluded that greater sensitivity to uncertainty and threat is 
associated with conservative (vs. liberal) preferences. Since then, a great number of studies have suggested that epistemic and existential motives play a role in conservative shift (Jost, 2017). Bonanno and Jost (2006), for example, found that high-exposure survivors of the September 11, 2001 terrorist attacks in New York City were much more likely to report that they had become more conservative (vs. more liberal) in the 18 months following the attacks. Echebarria-Echabe and Fernandez-Guede (2006) observed a similar pattern in response to the March 11, 2004 terrorist attacks in Madrid — both among people who were directly impacted by the threat (those living in the city) and those living further away. Thus, increased conservatism in response to system-level threats extends to "mere observers" (Nail \& McGregor, 2009).

Several studies point to an especially marked effect of system threat on hawkish foreign policy attitudes. Nail and McGregor (2009), for example, concluded that although 9/11 impacted general political attitudes (i.e., more negative evaluations of socialized medicine and more positive evaluations of conservatives), it most strongly affected evaluations of President George W. Bush and support for increased military spending. Experimental research by Lambert and colleagues (2010) demonstrated that the effects of terrorism reminders on U.S. participants' support for the president were restricted to those aspects having to do with his role as Commander-in-Chief of the military. These findings may not be too surprising given the nature of terrorist attacks, but they might be taken to indicate that conservative shift in the face of external threat is a purely strategic response - rather than one that is motivated, at least in part, by psychological defenses. That is, conservative shift with respect to military or foreign policy issues might simply reflect a rational tendency to respond aggressively in the face of a very real threat. Although we would not deny that the desire to avoid future harm plays some role in the 
public's response to terrorism, we submit that conservative shift following exposure to systemlevel threats is explained, at least in part, by increased motivation to justify the social system.

\section{The Mediating Role of System Justification}

According to system justification theory, individuals are motivated to perceive existing social, economic, and political arrangements to be relatively fair, legitimate, and justifiableeven when doing so may come at the expense of personal and group interests and esteem (Jost \& Van der Toorn, 2012). System justification motivation is associated with politically conservative leanings and with implicit as well as explicit preferences for order, stability, tradition, and conformity over chaos, flexibility, progress, and rebelliousness (Jost, Nosek, \& Gosling, 2008).

Contextual variability in system justification motivation has also been observed.

Exposure to criticisms of the social system (i.e., threats to the legitimacy or stability of the status quo) stimulates increased efforts to defend and bolster existing social arrangements (Liviatan \& Jost, 2014). A conceptual integration of studies involving system threat, political orientation, and system justification suggests a prominent role for system justification when it comes to the precipitation of "conservative shift," but this role has not been examined directly.

\section{Self-Related vs. System-Related Threats}

We investigate the hypothesis that threats to the system lead to increased conservatism because they activate a psychological process of motivated system defense. However, it is possible that threats to the system are experienced as ego threats and that conservative shift reflects an attempt to defend the self-concept in some way. Along these lines, terror management theory posits that ideological extremity and other defensive responses are instigated by threats to self-esteem and reminders of one's mortality (see Pyszczynski, Greenberg, \& Solomon, 1997). For instance, Landau and colleagues (2004) demonstrated that heightened concerns about 
mortality increased U.S. citizens' support for President George W. Bush and his counterterrorism policies (see also Jost, Stern, Rule, \& Sterling, 2017, for a comprehensive review of research in this area).

We propose that conservative shift in response to system threat has as much or more to do with the implications of threat for the legitimacy and stability of the system than the selfconcept. Some indirect support for this idea is provided by Kay, Jost, and Young (2005), who demonstrated that exposure to system criticism (vs. system affirmation) threatened the perceived legitimacy of the system without affecting either individual or collective self-esteem. In the research reported here, we explored whether a self-related threat (i.e., a threatening message concerning one's health) would affect social and political attitudes in the same manner as a system-related threat. This provides a more stringent test of the discriminant role of system threat in affecting conservative shift through increased system justification motivation.

\section{System Justification and Political Attitudes in Adolescents}

Few studies have examined system justification processes in children and adolescents, but there is some reason to believe that young people, like adults, will respond defensively to threats directed at the system. Henry and Saul (2006) observed status differences in system justification among Bolivian children (aged 10-15), such that children from lower status groups legitimized the Bolivian government more than children from higher status groups. Baron and Banaji (2009), too, noted system-justifying tendencies (such as outgroup favoritism) on tests of implicit attitudes in children aged 5 and younger. These results closely parallel those observed in adults in a wide variety of contexts (Jost, Banaji, \& Nosek, 2004; Van der Toorn, Feinberg, et al., 2015). By investigating conservative shift in adolescents, we not only contribute to a growing body of research on system justification in younger age groups but also provide a unique test of 
the effects of system-related threats in this demographic group. The results of such investigations, in turn, may inform theory and research concerning the developmental roots of political attitudes and behaviors.

\section{Method}

\section{Participants and Design}

Two hundred and three $9^{\text {th }}-12^{\text {th }}$ grade students attending a private high school in the Bronx, New York, participated in this study as part of a classroom exercise $(53.6 \%$ female; mean age $=15.96$ years old, $S D=1.19)$. Twenty participants were excluded for failing to follow instructions, leaving a final sample of 183 participants $(54.7 \%$ female; mean age $=15.98$ years old, $S D=1.19)$. Students were randomly assigned to one of three conditions in which they were exposed to: (1) an American system threat; (2) a personal health threat; or (3) a "no threat" control condition.

\section{Procedure}

The study was conducted in multiple classrooms on the same day. Participants were asked to read one of three passages, which were described as excerpts from longer pieces of journalism; these paragraphs manipulated a sense of threat. Participants were instructed to read the passage as many times as they deemed necessary, because they would be asked questions about it later. Next, participants were asked to complete a word-unscramble exercise, which served as a filler task. They then completed a general system justification scale as well as a scale assessing self-reported political conservatism. ${ }^{1}$

\section{Measures}

Threat manipulation. The system threat passage described flaws in the American social, economic, and political system (see Kay et al., 2005). Participants read, for example, that many 
citizens feel that the country has reached a low point and do not feel as safe and secure as they used to. The self-related threat passage described the deleterious effects of cell phone use on one's health. Participants read, for example, that researchers have shown a link between the use of cell phones and certain types of disease and that many people are disappointed that cell phone use is hazardous to long-term health. The no-threat passage, which served as our control condition, described house plant cultivation in a neutral way. Participants read, for example, that amateur botanists will spend many hours watering and pruning their plants and that gardening can become a very time consuming hobby for many people.

Word-unscramble task. Participants were presented with 15 strings of four letters each (e.g., "kobo") and asked to unscramble them. This served as a filler task to minimize any explicit connection participants might make between the threat manipulation and subsequent measures. Previous research has demonstrated that system threat manipulations may temporarily decrease satisfaction with the status quo when it is measured immediately after the threat (Kay et al, 2005). Some researchers advocate a post-threat delay (or distraction) because defensive, compensatory responses may arise only after a period of threat suppression (McGregor, Nail, Marigold, \& Kang, 2005).

System justification. Participants completed Kay and Jost's (2003) 8-item system justification scale using a response scale ranging from 1 (strongly disagree) to 9 (strongly agree). Sample items include: "In general, you find society to be fair" and "American society needs to be radically restructured" (reverse-coded; Cronbach's alpha $=.80$ ).

Political orientation. Participants were asked to indicate their political orientation on a response scale ranging from 1 (extremely liberal) to 9 (extremely conservative). To take into account the possibility that the adolescent participants had not yet formed stable political 
identities, or had not given much thought to politics, they were also given additional response options, namely never thought about it (0) and don't know (10). Four participants indicated never having thought about their political orientation $(2.2 \%$ of the total), eight participants reported not knowing their political orientation (4.4\%), and 10 participants declined to provide any response $(5.5 \%) .^{2}$ These participants were excluded from any analyses involving political orientation (remaining $N=161$ ).

\section{Results}

Two dummy codes were created for the system- and self-related threat conditions, with the control condition identified as the reference group. Descriptive statistics are reported in Table 1. We conducted a series of multiple regression analyses to test our hypothesis that system- (but not necessarily self-) related threats would increase participants' self-reported conservatism, compared to the control condition, and that this effect would be mediated by system justification

(see Table 2). ${ }^{3}$ Results of a first analysis in which system justification was regressed onto the two dummy codes revealed that system threat exerted a positive and significant effect on system justification, $b=.50, S E=.24, \beta=.18, t(180)=2.10, p=.037$, as hypothesized. By contrast, self-threat did not, $b=.23, S E=.25, \beta=.08, t(180)=.93, p=.355$. A second analysis in which political orientation was regressed onto the two types of threat revealed that participants assigned to the system threat condition identified themselves as significantly more conservative than did participants assigned to the control condition, $b=.52, S E=.26, \beta=.19, t(158)=2.05, p=.042$. Participants assigned to the self-threat condition did not differ from the control condition, $b=.36$, $S E=.27, \beta=.12, t(158)=1.34, p=.181$. A third analysis in which participants' political orientation was regressed onto system justification revealed that participants who scored higher on system justification reported being more conservative, $b=.57, S E=.07, \beta=.55, t(159)=8.26, p<.001$. 
When the threat dummy codes and system justification scores were simultaneously entered into a regression analysis predicting political orientation, the effect of system threat became non-significant, $b=.22, S E=.22, \beta=.08, t(157)=1.00, p=.318$, the effect of self-threat remained non-significant, $b=.20, S E=.23, \beta=.07, t(157)=.89, p=.374$, and the association between system justification and political orientation remained significant, $b=.56, S E=.07, \beta=.54$, $t(157)=7.94, p<.001$. To test the significance of the indirect path from system threat to political orientation through system justification, we used 1,000 bootstrapped resamples. Because the $95 \%$ bias-corrected confidence interval of $\{.059, .649\}$ did not contain 0 , the indirect effect was considered to be significant, consistent with the hypothesis that system justification mediates the effect of system threat on conservative shift. The indirect path from self-threat to political orientation was not significant, insofar as the interval of $\{-.101, .432\}$ contained 0 .

\section{Discussion}

The current research demonstrated that a threat to the system (but not the self) increased system justification as well as self-reported conservatism among adolescents, and that the effect of system threat on conservatism was mediated by system justification. Empirically, we distinguished this effect from the effect of self-related threat, which did not significantly affect system justification or political conservatism. ${ }^{4}$

These findings suggest that when the overarching social system is criticized or threatened, even adolescents may be drawn to conservative ideas and that this is attributable, at least in part, to a heightened desire to defend and bolster the status quo. As such, this research contributes to a fledgling (but growing) body of research on system justification processes in children and adolescents and provides a first examination of system threat effects in younger age groups. In demonstrating a mediational role for system justification, this study enriches the 
scientific understanding of conservative shift in response to threats directed at the social system (Jost, Stern, et al., 2017). It suggests that such effects are neither superficial nor purely strategic but are motivated, in part, by system justification concerns. Given that increased conservatism was observed in the system threat—but not the self-threat — condition, it appears that conservative shift may reflect an attempt to restore legitimacy and stability to the social system rather than the self-concept.

\section{Limitations}

There are several limitations of our study. Because this research was conducted in a private high school in New York City, we cannot be sure that the findings would generalize to adolescents in general (e.g., such as those attending public or parochial schools). This experiment is the first to demonstrate that conservative shift in response to system threat may be attributable to system justification motivation, but more research on children and adults is needed to assess the robustness and generalizability of this effect. Another limitation is that the design of this experiment did not allow us to demonstrate "conservative shift" directly, because we could not compare participants' political attitudes before and after exposure to the threat passages. We can, however, conclude that system threat increased system justification and political conservatism on average, insofar as the process of random assignment should have produced groups that were ideologically similar at baseline. The ideal research design would be one in which measures of political attitudes are taken days or perhaps weeks before (to minimize the problem of response anchoring) as well as after exposure to threat. This would be the only way to demonstrate ideological change in the same groups of individuals.

\section{Implications for Civic Engagement and Political Participation in Youth}


Insofar as system justification exerts a dampening effect on collective action aimed at bringing about social change (e.g., Jost, Becker, Osborne, \& Badaan, 2017), the current research may shed light on social psychological factors influencing youth political participation. Our findings suggest that threats to the social system (but not the self) may be expected to reduce such participation by increasing system justification motivation. This line of work may also be useful when it comes to theorizing about the developmental roots of political ideology and civic engagement, especially in circumstances (such as war, terrorist attacks, or economic crises) in which children are exposed to system-level threats. While a growing body of research documents the ubiquitous influence of political socialization processes (and the ways in which children's social and political attitudes are influenced by their parents, other family members, peers, teachers, and representatives of the media), our results indicate that such attitudes are affected by threats to the social system, too.

Finally, the results of our experiment lend credibility to the notion that conservative shift in response to system criticism or threat reflects a general motivational orientation (see also Liviatan \& Jost, 2014). In this sense, ideological defenses may stem from fairly fundamental aspects of human psychology, even when it comes to attitudes and behaviors of children and adolescents. Our species may therefore be regarded not only as a "political animal," as Aristotle famously suggested, but more specifically as an "ideological animal." 


\section{References}

Baron, A., \& Banaji, M. R. (2009). Evidence of system justification in young children. Social and Personality Psychology Compass, 3, 918-926. DOI: 10.1111/j.17519004.2009.00214.x

Bonanno, G. A., \& Jost, J. T. (2006). Conservative shift among high-exposure survivors of the September 11th terrorist attacks. Basic and Applied Social Psychology, 28, 311-323. DOI: $10.1207 /$ s15324834basp2804_4

Burke, B. L., Kosloff, S., \& Landau, M. J. (2013). Death goes to the polls: A meta-analysis of mortality salience effects on political attitudes. Political Psychology, 34, 183-200. DOI: $10.1111 /$ pops. 12005

Echebarria-Echabe, A., \& Fernandez-Guede, E. (2006). Effects of terrorism on attitudes and ideological orientation. European Journal of Social Psychology, 36, 259-265. DOI: 10.1002/ejsp.294

Henry, P. J., \& Saul, A. (2006). The development of system justification in the developing world. Social Justice Research, 19, 365-378. DOI: 10.1007/s11211-006-0012-x

Jost, J. T. (2017). Ideological asymmetries and the essence of political psychology. Political Psychology, 38, 167-208. DOI: 10.1111/pops.12407

Jost, J. T., Banaji, M. R., \& Nosek, B. A. (2004). A decade of system justification theory: Accumulated evidence of conscious and unconscious bolstering of the status quo. Political Psychology, 25, 881-920. DOI: 10.1111/j.1467-9221.2004.00402.x

Jost, J. T., Becker, J., Osborne, D., \& Badaan, V. (2017). Missing in (collective) action: Ideology, system justification, and the motivational antecedents of protest behavior. 
Current Directions in Psychological Science, 26, 99-108. DOI:

\section{$10.1177 / 0963721417690633$}

Jost, J. T., Glaser, J., Kruglanski, A. W., \& Sulloway, F. (2003). Political conservatism as motivated social cognition. Psychological Bulletin, 129, 339-375. DOI: 10.1037/00332909.129.3.339

Jost, J. T., Nosek, B. A., \& Gosling, S. D. (2008). Ideology: Its resurgence in social, personality, and political psychology. Perspectives on Psychological Science, 3, 126-136. DOI: $10.1111 / j .1745-6916.2008 .00070 . x$

Jost, J. T., Stern, C., Rule, N. O., \& Sterling, J. (2017). The politics of fear: Is there an ideological asymmetry in existential motivation? Social Cognition, 35, 324-353. DOI: $10.1521 /$ soco.2017.35.4.324

Jost, J. T., \& Van der Toorn, J. (2012). System justification theory. In P. A. M. van Lange, A. W. Kruglanski, \& E. T. Higgins (Eds.), Handbook of theories of social psychology (pp. 313343). London: Sage.

Kay, A. C., \& Jost, J. T. (2003). Complementary justice: Effects of "poor but happy" and "poor but honest" sterotype exemplars on system justification and implicit activation of the justice motive. Journal of Personality and Social Psychology, 85, 823-837. DOI: $10.1037 / 0022-3514.85 .5 .823$

Kay, A. C., Jost, J. T., \& Young, S. (2005). Victim derogation and victim enhancement as alternate routes to system justification. Psychological Science, 16, 240-246. DOI: 10.1111/j.0956-7976.2005.00810.x

Lambert, A. J., Scherer, L. D., Schott, J. P., Olsen, K. R., Andrews, R., O’Brien, T. \& Zisser, A. R. (2010). Rally effects, threat, and attitude change: An integrative approach to 
understanding the role of emotion. Journal of Personality and Social Psychology, 98, 886-903. DOI: $10.1037 / \mathrm{a} 0019086$

Landau, M. J., Solomon, S., Greenberg, J., Cohen, F., Pyszczynski, T., Arndt, J., Miller, C. H., Ogilvie, D. M., \& Cook, A. (2004). Deliver us from evil: The effects of mortality salience and reminders of 9/11 on support for President George W. Bush. Personality and Social Psychology Bulletin, 30, 1136-1150. DOI: 10.1177/0146167204267988

Liviatan, I., \& Jost, J. T. (2014). A social-cognitive analysis of system justification goal striving. Social Cognition, 32, 95-129. DOI: 10.1521/soco.2014.32.2.95

Markus, G. B. (1986). Stability and change in political attitudes: Observed, recalled, and "explained." Political Behavior, 8, 21-44. https://doi.org/10.1007/BF00987591

McGregor, I., Nail, P. R., Marigold, D. C., \& Kang, S-J. (2005). Defensive pride and consensus: Strength in imaginary numbers. Journal of Personality and Social Psychology, 89, 978996. DOI: $10.1037 / 0022-3514.89 .6 .978$

Nail, P. R., \& McGregor, I. (2009). Conservative shift among liberals and conservatives following 9/11/01. Social Justice Research, 22, 231-240. DOI: 10.1007/s11211-009$0098-\mathrm{z}$

Nail, P. R., McGregor, I., Drinkwater, A., Steele, G., \& Thompson, A. (2009). Threat causes liberals to think like conservatives. Journal of Experimental Social Psychology, 45, 901907. DOI: 10.1016/j.jesp.2009.04.013

Pyszczynski, T., Greenberg, J., \& Solomon, S. (1997). Why do we need what we need? A terror management perspective on the roots of human social motivation. Psychological Inquiry, 8, 1-20.10.1207/s15327965pli0801_1 
Schüller, S. (2015). The 9/11 conservative shift. Economics Letters, 135, 80-84. DOI: 10.1016/j.econlet.2015.07.031

Thórisdóttir, H., \& Jost, J. T. (2011). Motivated closed-mindedness mediates the effect of threat on political conservatism. Political Psychology, 32, 785-811. DOI: 10.1111/j.14679221.2011.00840.x

Van der Toorn, J., Feinberg, M., Jost, J. T., Kay, A. C., Tyler, T. R., Willer, R., \& Wilmuth, C. (2015). A sense of powerlessness fosters system justification: Implications for the legitimation of authority, hierarchy, and government. Political Psychology, 36, 93-110. DOI: $10.1111 /$ pops. 12183 
Table 1. Descriptive statistics per condition

\begin{tabular}{lcccccc}
\hline & \multicolumn{2}{c}{$\begin{array}{c}\text { System } \\
\text { threat }\end{array}$} & \multicolumn{2}{c}{$\begin{array}{c}\text { Self } \\
\text { threat }\end{array}$} & \multicolumn{2}{c}{ Control } \\
& $M$ & $S D$ & $M$ & $S D$ & $M$ & $S D$ \\
\hline & 4.75 & 1.40 & 4.48 & 1.29 & 4.25 & 1.26 \\
System justification & 3.48 & 1.55 & 3.32 & 1.15 & 2.96 & 1.23 \\
Political orientation & 16.18 & 1.17 & 15.88 & 1.24 & 15.86 & 1.16 \\
Age & & & & & &
\end{tabular}

Table 2. Regression analyses

\begin{tabular}{lccc}
\hline Variable & $b$ & $S E b$ & $\beta$ \\
\hline$D V=$ system justification & & & \\
System (vs. control) threat & 0.50 & 0.24 & $.18^{*}$ \\
Self (vs. control) threat & 0.23 & 0.25 & .08 \\
\hline$D V=$ political orientation & & & \\
System (vs. control) threat & 0.52 & 0.26 & $.19^{*}$ \\
Self (vs. control) threat & 0.36 & 0.27 & .12 \\
\hline$D V=$ political orientation & & & \\
System justification & 0.57 & 0.07 & $0.55^{* * *}$ \\
\hline$D V=$ political orientation & & & \\
System (vs. control) threat & 0.22 & 0.22 & 0.08 \\
Self (vs. control) threat & 0.20 & 0.23 & 0.07 \\
System justification & 0.56 & 0.07 & $0.54^{* * *}$ \\
\hline
\end{tabular}

Note. ${ }^{*} p<.05,{ }^{* * *} p<.001$. 


\section{Acknowledgments}

We thank Anesu Mandisodza for her help in designing the self-threat and control conditions of the experiment.

\section{Footnotes}

${ }^{1}$ This study was originally conducted as part of an Intel Science Competition Project by the third author which had broader objectives than the current study. It included measures assessing participants' discomfort with ambiguity, their endorsement of private schooling, and their identification with several social groups. In addition, it included a group threat condition in which participants read about the negative implications of private schools and an irrelevant threat condition in which participants read about the dismal state of houseplant cultivation practices. Compared to the control condition, neither of these threat conditions significantly affected system justification or political orientation.

2 These percentages are fairly low compared to previous research on political orientation in adolescents. Markus (1986), for example, reported that $14 \%$ of respondents opted out of the ideological self-placement item included in his study.

${ }^{3}$ Statistically adjusting for participant sex and age yielded very similar findings. There was a significant main effect of participant sex such that girls scored significantly higher than boys on system justification and conservatism.

${ }^{4}$ Although the current research suggests a distinctive role for system justification motivation concerning the relationship between system threat and political conservatism, we would not go so far as to suggest that threats to the self would never affect political orientation (e.g., see Burke, Kosloff, \& Landau, 2013; Jost, Stern, Rule, \& Sterling, 2017; Thórisdóttir \& Jost, 2011). We would suggest, however, that such effects would not necessarily be mediated by increased system justification. 